\title{
Guest Editorial: Implications for practice
}

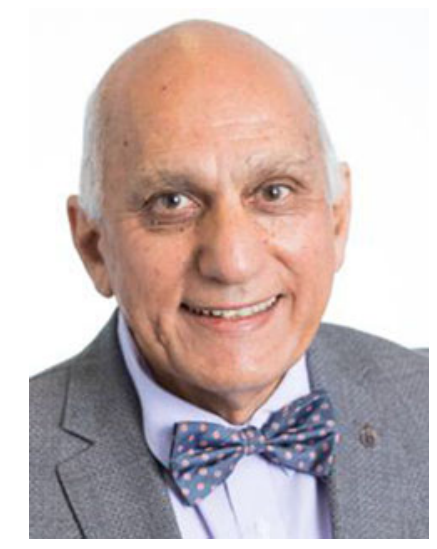

Dr James A. Athanasou

Welcome to this special issue of the Australian Journal of Rehabilitation Counselling.

Late last year, I was asked by the Australian Society of Rehabilitation Counsellors to curate an issue with at least shorter and hopefully more readable articles. There was a call for papers and contributors for this guest issue were invited to produce papers within a defined framework. The brief was to provide articles which were likely to be relevant to a professional rehabilitation audience. The spread of articles had to be of wide interest. The articles needed to be shorter than traditional academic articles. The papers should not be overburdened by citations and references in the text or characterized by complex statistical analyses. Case studies and position papers were welcomed. Within these parameters it was considered possible to still provide a high-quality academic contribution that is readable.

As a point of departure from most academic journals, I asked the contributors to provide a brief biographical note and photo to accompany their paper, in order to give the reader some personal background. To round out the approach for the special issue, I requested authors to produce three review questions and answers. These serve as a type of self-checking of understanding in order to aid professional development.

To its credit, the Australian Society of Rehabilitation Counsellors supported the initiative for a special issue under the banner of implementations for Practice. It is a small but tentative step in responding to the needs of its members. It aims at a return to the origins of the academic journal as a means of communication of findings among peers in a learned society.

In preparing this issue, I am grateful for the publishing liaison of Dr Richard Hecker with the Cambridge University Press. I thank also the production team at Cambridge for making this issue a reality.

I would like to acknowledge the cooperation of the Editor, Professor Elias Mpofu in putting together this special issue. In particular, I take the opportunity to mention his dedication to the 
Australian Journal of Rehabilitation Counselling. He has ensured that it is now up to date in production and recognized internationally as an academic outlet for rehabilitation research.

Finally, one hopes that such special issues and publishing initiatives recur from time to time. I hope that you enjoy the spread of articles produced for you by a wide range of local and international authors. Once again, I thank the Australian Society of Rehabilitation Counsellors for its forward thinking and concern for its professional members.

\author{
Dr James A. Athanasou \\ Associate Professor [Honorary] \\ The University of Sydney \\ Adjunct Professor University of Southern Queensland \\ Australian Collaboratory for Career Employment and Learning for Living \\ March 2020.
}

Cite this article: Athanasou JA (2020). Guest Editorial: Implications for practice. The Australian Journal of Rehabilitation Counselling 26, 1-2. https://doi.org/10.1017/jrc.2020.11 